\title{
Double-Poling Physiology and Kinematics of Elite Cross-Country Skiers: Specialized Long-Distance Versus All-Round Skiers
}

\author{
Øyvind Skattebo, Thomas Losnegard, and Hans Kristian Stadheim
}

\begin{abstract}
Purpose: Long-distance cross-country skiers specialize to compete in races $>50 \mathrm{~km}$ predominantly using double poling (DP). This emphasizes the need for highly developed upper-body endurance capacities and an efficient DP technique. The aim of this study was to investigate potential effects of specialization by comparing physiological capacities and kinematics in DP between long-distance skiers and skiers competing using both techniques (skating/classic) in several competition formats ("all-round skiers"). Methods: Seven male long-distance (32 [6] y, 183 [6] cm, 76 [5] kg) and 6 all-round (25 [3] y, 181 [5] cm, 75 [6] kg) skiers at high international levels conducted submaximal workloads and an incremental test to exhaustion for determination of peak oxygen uptake ( $\mathrm{VO}_{2}$ peak) and time to exhaustion (TTE) in DP and running. Results: In DP and running maximal tests, TTE showed no difference between groups. However, long-distance skiers had 5-6\% lower $\mathrm{VO}_{2}$ peak in running (81 [5] vs 85 [3] $\left.\mathrm{mL} \cdot \mathrm{kg}^{-1} \cdot \mathrm{min}^{-1} ; P=.07\right)$ and DP $\left(73[3]\right.$ vs $\left.78[3] \mathrm{mL} \cdot \mathrm{kg}^{-1} \cdot \mathrm{min}^{-1} ; P<.01\right)$ than all-round skiers. In DP, long-distance skiers displayed lower submaximal $\mathrm{O}_{2}$ cost than all-round skiers $(3.8 \pm 3.6 \% ; P<.05)$ without any major differences in cycle times or cyclic patterns of joint angles and center of mass. Lactate concentration over a wide range of speeds (45-85\% of $\mathrm{VO}_{2}$ peak) did not differ between groups, even though each workload corresponded to a slightly higher percentage of $\mathrm{VO}_{2}$ peak for long-distance skiers (effect size: 0.30-0.68). Conclusions: The long-distance skiers displayed lower $\mathrm{VO}_{2}$ peak but compensated with lower $\mathrm{O}_{2}$ cost to perform equally with the all-round skiers on a short TTE test in DP. Furthermore, similar submaximal lactate concentration and reduced $\mathrm{O}_{2}$ cost could be beneficial in sustaining high skiing speeds in long-duration competitions.
\end{abstract}

Keywords: cross-country skiing, oxygen cost, exercise economy, lactate threshold, peak oxygen uptake

Because of the wide range of physiological, biomechanical, and anthropometrical demands in endurance sports, specialization is often considered a prerequisite for reaching an elite performance level. As an example, marathon runners display lower maximal oxygen uptake $\left(\mathrm{VO}_{2} \mathrm{max}\right)$ than 5 - to 10-km runners but compensate with a lower $\mathrm{O}_{2}$ cost of running to achieve superior performance in long events. ${ }^{1}$ Similarly, road cyclists who are uphill, flat, or timetrial specialists generally display anthropometrics and indexed $\mathrm{VO}_{2}$ max values that are favorable for performance on either uphill or flat terrain, respectively. ${ }^{2,3}$

Cross-country (XC) skiing is a complex endurance sport consisting of several competition formats with durations ranging from $\sim 3$ minutes (sprint, $\sim 1.3-1.8 \mathrm{~km}$ ) to more than 2 hours $(\leq 50 \mathrm{~km})$ in World Cup (WC) and Olympic events. Consequently, an increasing number of athletes specialize, mainly competing in 1 or a few race formats to optimize physiological performance and rank; elite sprint-specialized skiers are heavier and have a larger anaerobic capacity but display lower body mass normalized

(C) 2019 The Authors. Published by Human Kinetics, Inc. This is an Open Access article distributed under the terms of the Creative Commons Attribution License CC BY NC 4.0, which permits unrestricted noncommercial use, distribution, and reproduction in any medium, provided the original work is properly cited, the new use includes a link to the license, and any changes are indicated. See http:// creativecommons.org/licenses/by-nc/4.0. This license does not cover any third-party material which may appear with permission in the article. For commercial use, permission should be requested from Human Kinetics, Inc., through the Copyright Clearance Center (http://www.copyright.com).

The authors are with the Dept of Physical Performance, Norwegian School of Sport Sciences, Oslo, Norway. Skattebo (oyvind.skattebo@nih.no) is corresponding author.
$\mathrm{VO}_{2}$ max compared with distance $\mathrm{XC}$ skiers, most likely due to a combination of genetics and training specificity. ${ }^{4}$

Recently, long-distance mass-start races such as the Ski Classics (a cup of long races separated from the WC), where athletes compete for $\sim 40$ to $90 \mathrm{~km}$ using the classical technique, have become increasingly popular, and several male and a few female athletes have specialized their training to optimize performance in such events. Currently, very little is known about these "long-distance skiers," 5 and knowledge about the top athletes" physiological capacities could provide useful information for athletes and coaches with regard to this race format's specific demands. Because of the track layouts, improvements in equipment and track preparation allowing for higher speeds, and current trends, elite long-distance skiers use skis without grip wax and rely exclusively on the double poling (DP) technique in the majority of events. This is intriguing as DP relies solely on propulsion trough the poles, emphasizing the need for a well-developed upper-body capacity. ${ }^{5}$ Hence, long-distance skiers exercise their upper body frequently and may possess other physiological and technical qualities related to DP compared with "all-round skiers" who compete using both the skating and classical techniques in several race formats. In fact, only specialists have won the longest Ski Classics event over the last decade (Vasaloppet, $90 \mathrm{~km}$ ), even though several world-class all-round skiers have competed.

During the last decade, the DP technique has been extensively analyzed, with studies focusing on different inclines, ${ }^{6}$ poling frequencies, ${ }^{7}$ subgroups of athletes, ${ }^{8}$ and kinematic changes during a race. ${ }^{9}$ However, to our knowledge, studies investigating the physiology and the technique of DP specialists are lacking. The only study to date found lower submaximal $\mathrm{O}_{2}$ cost and blood lactate concentrations ([La- $]$ ) in DP and equal $\mathrm{VO}_{2}$ peak in both DP and diagonal skiing in elite long-distance skiers compared with 
all-round skiers. However, as the all-round skiers were defined as national class skiers with mean International Ski Federation's (FIS) points as high as 121, it is questionable if these findings can be extrapolated to the elite performance level. Hence, it is currently unknown whether the long-distance skiers' specialization with respect to training, to perform in long events using predominantly the DP technique, leads to any favorable technical or physiological adaptations compared with the elite all-round skiers.

The XC skiers are normally found to reach a peak oxygen uptake $\left(\mathrm{VO}_{2}\right.$ peak) of "only" $\sim 90 \%$ of $\mathrm{VO}_{2}$ max measured in diagonal skiing or $\mathrm{VO}_{2}$ peak running when they do incremental exercise tests to exhaustion in DP.10-12 Although recently contradicted, ${ }^{13}$ this may partly be explained by the upper-body muscles having longer diffusional distances, shorter mean transit times, and lower oxidative capacity than leg muscles, even in well-trained XC skiers. ${ }^{14-16}$ Therefore, arm $\mathrm{O}_{2}$ extraction is found to be $\sim 10 \%$ lower than in leg muscles ${ }^{16}$ and contributes, together with a lower vascular conductance, ${ }^{17}$ to the $\sim 10 \%$ lower $\mathrm{VO}_{2}$ peak observed in DP. Recently, it was suggested that training designed to enhance $\mathrm{O}_{2}$ extraction in the arms, such as high-volume, low-intensity upper-body training, could improve the DP $\mathrm{VO}_{2}$ peak/ $/ \mathrm{VO}_{2}$ max ratio. ${ }^{18}$ Therefore, investigating this ratio in long-distance skiers could give some indication of whether the limiting factors can be improved with increased training specificity.

Hence, the present investigation aimed to (1) provide information regarding physiological capacities of elite male long-distance $\mathrm{XC}$ skiers and (2) investigate potential effects of specialization by comparing their physiological capacities and kinematics in DP to those of elite all-round skiers.

\section{Methods}

\section{Subjects}

Of the elite male long-distance skiers included in the present study, 6 of the 7 had podium placements in the (Marcialonga, Vasaloppet, Birkebeinerrennet, etc) Ski Classics and were ranked among the top 10 in the overall standings during the season they were tested in. All 6 male all-round skiers had competed in the FIS WC, with 5 of them finishing top 5 in 1 or more individual races in the previous season (Table 1). Within 2 seasons from data collection, the group of all-round skiers included 1 Olympic and 1 world champion (only individual races considered). The long-distance skiers were older than the all-round skiers $(P=.04)$. However, this difference was not entirely an effect of our sampling, as it also existed between the top $10 \mathrm{WC}$ and Ski Classics skiers (28.3 [3.9] vs 31.6 [5.9]; $P=.07$; season 2016-2017). All skiers were familiarized with treadmill testing, both in DP and running. The subjects were fully aware of the nature of the study and signed a written informed consent before participation. The study was approved by the ethical committee of the Norwegian School of Sport Sciences (05-130617) and reported to the Norwegian Center for Research Data (54405).

\section{Methodology}

Testing was conducted in the late preparation phase (October) and consisted of submaximal workloads and an incremental test to exhaustion in DP, followed by a similar test in running $\sim 1.5$ hours later (nonrandomized). The subjects were allowed to drink a carbohydrate and electrolyte-containing fluid ad libitum during breaks and to eat a small snack (such as an energy bar) between tests. The rationale for performing both tests on the same day was that the participants were elite skiers and that the testing needed to fit their schedule to recruit this highly trained group. The DP test was conducted first as we analyzed kinematics only in DP and as the DP data were evaluated as being the most important with respect to the purpose of the study. This may have affected submaximal and peak responses in running, but unlikely differently in the 2 groups. The day before testing, the skiers were restricted to perform any strenuous training $(>75 \%$ of maximum heart rate $[\mathrm{HR}]$ or strength training).

Instruments. Oxygen uptake $\left(\mathrm{VO}_{2}\right)$ was measured using opencircuit indirect calorimetry with a mixing chamber (Oxycon Pro; Jaeger Instrument, Hoechberg, Germany) ${ }^{19}$ calibrated as previously described. ${ }^{20} \mathrm{HR}$ was measured continuously (Polar RS800; Polar Electro Oy, Kempele, Finland) and $\left[\mathrm{La}^{-}\right]$was measured in nonhemolyzed capillary fingertip blood (YSI 1500 Sport; Yellow Springs Instruments, Yellow Springs, OH). The roller-ski testing was conducted on a $3 \times 4.5-\mathrm{m}$ treadmill (Rodby, Sodertalje, Sweden). As a precautionary measure, the athletes wore a safety harness connected to an automatic emergency brake. The rolling friction coefficient $(\mu=0.021)$ of the roller skis (Swenor, Sarpsborg, Norway) was tested before, during, and after the experiments $^{21}$ and was unchanged during the study. Work rate was calculated as the sum of power against gravity $\left(P_{\mathrm{g}}\right)$ and friction $\left(P_{\mathrm{f}}\right)$ :

$$
\text { Work rate }=P_{g}+P_{f}=m g v(\sin (\alpha)+\cos (\alpha) \times \mu)
$$

where $m$ is the sum of body mass and mass of equipment (in kilograms), $g$ is the gravitational constant, $v$ is the speed of the treadmill belt (in meters per second), $\alpha$ is the treadmill incline (in degrees), and $\mu$ is the frictional coefficient.

\section{Table 1 Characteristics of the 6 All-Round Skiers and 7 Long-Distance Skiers Included in the Study}

\begin{tabular}{lccc}
\hline & All-round skiers & Long-distance skiers & ES (Cohen $\boldsymbol{d})$ \\
\hline Age, $\mathrm{y}$ & $25.4(2.6)$ & $32.0(6.3)^{*}$ & $1.31^{\mathrm{La}}$ \\
Body height, cm & $181(5)$ & $183(6)$ & $0.32^{\mathrm{S}}$ \\
Body mass, $\mathrm{kg}$ & $75.1(5.5)$ & $75.7(5.2)$ & $0.11^{\mathrm{T}}$ \\
Body mass index, $\mathrm{kg} \cdot \mathrm{m}^{-2}$ & $23.0(1.1)$ & $22.7(0.8)$ & $0.26^{\mathrm{S}}$ \\
FIS points (distance) $2016 / 2017$ & $16.0(12.4)$ & $38.1(6.5)^{*}$ & $2.29^{\mathrm{VL}}$ \\
Ranking Ski Classics 2016/2017 & - & $6.9(6.0)$ & - \\
\hline
\end{tabular}

Note: Data are presented as mean (SD). Abbreviations: ES, effect size; FIS, International Ski Federation. Note: Superscript letters by the ESs denote their magnitude as ${ }^{\mathrm{T}}$, trivial $(\mathrm{ES}<0.2) ;{ }^{\mathrm{S}}$, small $(0.2 \leq \mathrm{ES}<0.6){ }^{\mathrm{M}}$, moderate $(0.6 \leq \mathrm{ES}<1.2)$; ${ }^{\mathrm{La}}$, large $(1.2 \leq \mathrm{ES}<2.0)$; and ${ }^{\mathrm{VL}}$, very large $(\mathrm{ES} \geq 2.0) .^{23}$ The races in the Ski Classics Cup were in season 2016/2017 given a penalty of 35 points when FIS points were calculated as compared with 0 in World Cup, World Championship, or Olympic races.

$*$ Significant difference between groups $(P<.05)$. 
The poles (Triac 1.0; Swix, Lillehammer, Norway) were standardized to the nearest length $(2.5 \mathrm{~cm}$ intervals $)$ that corresponded to $88 \%$ of the athletes' body height, as pole length has been shown to influence submaximal $\mathrm{O}_{2}$ cost, kinematics, and performance. $^{22}$ The poles were $3.0(1.0) \mathrm{cm}$ longer than the maximum length allowed during competition the following winter (measured from pole tip to strap insertion), according to the new FIS regulation $(84.7 \pm 0.5 \%$ of the body height including shoes instead of $83 \%$ ). Therefore, kinematic data may be affected by this, but unlikely any differently in the 2 groups as all subjects were familiarized to long pole lengths. An inertial measurement system (PLUX Wireless Biosignals S.A., Lisbon, Portugal) sampling at $1000 \mathrm{~Hz}$ was mounted on the skier's right pole, and the cycle time, poling time, and reposition time were calculated on the basis of 10 consecutive cycles for each submaximal workload as previously described. ${ }^{24}$ Joint angles were derived from $50-\mathrm{Hz}$ video analysis in the sagittal plane (Canon HF100; Canon Inc, Tokyo, Japan) using Tracker (Tracker version 4.95; Douglas Brown, Open Source Physics). ${ }^{22}$ The vertical center of mass (zCOM) was calculated as the weighted average of the COMs of each body segment and equipment, as previously described. ${ }^{22}$ The running test was conducted using a custom-made treadmill (Woodway GmbH, Weil am Rhein, Germany).

DP Test. All DP workloads were conducted at $2.5^{\circ}$ incline, with the incline and speeds chosen to induce competition-relevant technique based on pilot testing and previous research. ${ }^{22}$ The subjects warmed up for 15 minutes at $10.8 \mathrm{~km} \cdot \mathrm{h}^{-1}(\sim 60 \%-70 \%$ of $\left.\mathrm{HR}_{\text {peak-DP}}\right)$, with the last 5-minute serving as the first submaximal workload. Thereafter, the speed was increased by $1.8 \mathrm{~km} \cdot \mathrm{h}^{-1}$ $\left(0.5 \mathrm{~m} \cdot \mathrm{s}^{-1}\right)$ in each 5 -minute step until the lactate threshold was exceeded. The estimated lactate threshold was defined as the highest speed before the $\left[\mathrm{La}^{-}\right]$on the first workload $+1.8 \mathrm{mmol} \cdot \mathrm{L}^{-1}$ was exceeded, which corresponds well with the maximal lactate steady-state workload in DP. ${ }^{26}$ The athletes completed a total of 6 to 7 submaximal workloads $\left(10.8-21.6 \mathrm{~km} \cdot \mathrm{h}^{-1} ; \sim 45 \%-85 \%\right.$ of $\mathrm{VO}_{2}$ peak-DP), always separated by 1.5 -minute breaks during which [ $\left.\mathrm{La}^{-}\right]$was immediately assessed. Cardiorespiratory variables were monitored continuously, and the averages of the last 2 minutes of each workload served as the steady-state values. After a 7 -minute break including rest and active recovery $(-40 \%$ of $\mathrm{VO}_{2}$ peak-DP), the incremental test started at $18 \mathrm{~km} \cdot \mathrm{h}^{-1}$ and progressed with increases of $0.9 \mathrm{~km} \cdot \mathrm{h}^{-1}$ for every 30 seconds completed. Performance was defined as time to exhaustion (TTE). Thirty seconds and 3 minutes after exhaustion, [ $\left.\mathrm{La}^{-}\right]$was assessed and the highest value was used as $\left[\mathrm{La}^{-}\right.$peak $]$. The highest continuous $\mathrm{VO}_{2}$ during a 30-second period and the highest $\mathrm{HR}$ during a 5-second period were defined as $\mathrm{VO}_{2}$ peak-DP and $\mathrm{HR}_{\text {peak-DP, }}$ respectively. The mean speed during the last 30 seconds before exhaustion was defined as the peak speed $\left(\operatorname{speed}_{\text {peak }}\right)$. Peak aerobic speed $\left(\mathrm{sVO}_{2}\right.$ peak) was calculated as the minimal speed requiring a $\mathrm{VO}_{2}$ equal to $\mathrm{VO}_{2}$ peak from each individual's relationship between submaximal $\mathrm{O}_{2}$ cost and treadmill speed.

Running Test. The running test was performed at a $6^{\circ}$ incline and was similar in structure to the DP test. Briefly, the test started at $7.5 \mathrm{~km} \cdot \mathrm{h}^{-1}\left(\sim 60-70 \%\right.$ of $\left.\mathrm{HR}_{\text {max-RUN }}\right)$ and progressed with increments of $0.9 \mathrm{~km} \cdot \mathrm{h}^{-1}$ for each 5-minute step until the lactate threshold was exceeded (workload range: $7.5-12.9 \mathrm{~km} \cdot \mathrm{h}^{-1} ; \sim 50$ $85 \%$ of $\mathrm{VO}_{2}$ peak-RUN). The estimated lactate threshold was defined as the highest speed before the $\left[\mathrm{La}^{-}\right]$on the first workload $+1.5 \mathrm{mmol} \cdot \mathrm{L}^{-1}$ was exceeded, which corresponds well with the maximal lactate steady-state workload in running. ${ }^{25}$ Cardiorespiratory variables were monitored during the last 2.5 minutes of each workload, and the average over the last 2 minutes was used for further analysis. After a 7-minute break including active recovery $\left(\sim 35 \%\right.$ of $\mathrm{VO}_{2}$ peak-RUN), the incremental test started at $10 \mathrm{~km} \cdot \mathrm{h}^{-1}\left(\sim 70 \%\right.$ of $\mathrm{VO}_{2}$ peak-RUN $)$ and progressed with increases of $0.5 \mathrm{~km} \cdot \mathrm{h}^{-1}$ for every 30 seconds completed until exhaustion. The highest continuous $\mathrm{VO}_{2}$ during a 60 -second period was defined as $\mathrm{VO}_{2}$ peak-RUN instead of $\mathrm{VO}_{2} \mathrm{max}$, as it has been previously shown that $\mathrm{XC}$ skiers can reach $3 \%-4 \%$ higher values during diagonal skiing compared with running. ${ }^{11,27}$ The highest HR during a 5-second period was defined as $\mathrm{HR}_{\text {peak-RUN }}$.

Training Data. Annual endurance training (May 1 to April 30) was recorded in training diaries and categorized into training modes (skating, classical, running, or other) and intensity zones based on the session-goal approach. ${ }^{28}$ In addition, the training times spent engaged in speed training and strength training were recorded. Unfortunately, only 3 of the 7 long-distance skiers recorded their training regularly, and their records were used in the comparison with the 6 all-round skiers. Due to the small sample size, no statistical analysis regarding the group comparison was performed.

\section{Statistical Analysis}

Group means and group differences are shown as mean (SD) and mean $\pm 95 \%$ confidence interval. The data were normally distributed as assessed by Shapiro-Wilk test. Group differences were analyzed with unpaired Student $t$ tests and 2-factor mixed analysis of variance (group $\times$ speed on submaximal and group $\times$ exercise mode on peak values). If a significant group effect was found, a Bonferroni post hoc test for multiple comparisons was conducted. Moreover, analysis of covariance was conducted on the $\mathrm{VO}_{2}$ peak values using age as a covariate. Effect sizes (ESs; Cohen $d$ ) and correlation coefficients (Pearson product-moment correlation) were classified according to Hopkins. ${ }^{22}$ The alpha level was set to .05 and $P$ values between .05 and .10 were considered to indicate trends. IBM SPSS Statistics 24.0 (IBM Corp, New York, NY) was used for statistical analysis.

\section{Results \\ Incremental Test to Exhaustion}

There was a significant main effect of group on body-mass normalized $\mathrm{VO}_{2}$ peak $\left(F_{1,11}=7.2, P=.02\right)$, with post hoc tests revealing $5.3 \pm 5.8 \%(P=.07)$ and $6.4 \pm 4.1 \%(P<.01)$ higher $\mathrm{VO}_{2}$ peak-RUN and $\mathrm{VO}_{2}$ peak-DP for all-round compared with long-distance skiers, respectively. When adjusted for age, there was still a significant group-difference of $6.5 \pm 5.3 \%\left(F_{1,10}=7.3\right.$, $P=.02)$ in $\mathrm{VO}_{2}$ peak-DP but no difference in $\mathrm{VO}_{2}$ peak-RUN (difference: $4.8 \pm 7.6 \% ; F_{1,10}=2.0, P=.19$ ). No group differences were found for the ratio $\mathrm{VO}_{2}$ peak-DP/ $\mathrm{VO}_{2}$ peak-RUN $(0.92$ [0.03] vs 0.91 [0.03] for all-round [range: 0.88-0.95] and long-distance skiers [range: $0.87-0.94$ ], respectively; $P=.48$; ES: 0.41$)$, TTE or the remaining cardiorespiratory variables (Table 2). A moderate negative correlation was found between $\mathrm{VO}_{2}$ peak-RUN and the ratio $\mathrm{VO}_{2}$ peak-DP/VO 2 peak-RUN $(r=-.48 ; P=.09 ; \mathrm{n}=13)$. Age had a moderate negative correlation with $\mathrm{VO}_{2}$ peak-RUN $(r=-.35 ; P=.24$; $\mathrm{n}=13)$ and $\mathrm{VO}_{2}$ peak-DP $(r=-.40 ; P=.18 ; \mathrm{n}=13)$. 
Table 2 Performance and Physiological Response During Incremental Tests to Exhaustion in Running (6.0 Incline) and Double Poling (2.5 Incline)

\begin{tabular}{|c|c|c|c|c|c|c|}
\hline & \multicolumn{3}{|c|}{ Running } & \multicolumn{3}{|c|}{ Double poling } \\
\hline & $\begin{array}{c}\text { All-round } \\
\text { skiers }(n=6)\end{array}$ & $\begin{array}{l}\text { Long-distance } \\
\text { skiers }(n=7)\end{array}$ & $\begin{array}{c}\text { ES } \\
\text { (Cohen } d)\end{array}$ & $\begin{array}{c}\text { All-round } \\
\text { skiers }(n=6)\end{array}$ & $\begin{array}{l}\text { Long-distance } \\
\text { skiers }(n=7)\end{array}$ & $\begin{array}{c}\text { ES } \\
(\text { Cohen } d)\end{array}$ \\
\hline Time to exhaustion, $\mathrm{s}$ & $446(24)$ & $423(37)$ & $0.73^{\mathrm{M}}$ & $269(20)$ & $268(22)$ & $0.06^{\mathrm{T}}$ \\
\hline Speed $_{\text {peak }}, \mathrm{km} \cdot \mathrm{h}^{-1}$ & $16.7(0.4)$ & $16.3(0.6)$ & $0.73^{\mathrm{M}}$ & $25.2(0.6)$ & $25.1(0.6)$ & $0.06^{\mathrm{T}}$ \\
\hline Power $_{\text {peak }}, \mathrm{W}$ & - & - & - & $353(25)$ & $354(18)$ & $0.05^{\mathrm{T}}$ \\
\hline $\begin{array}{l}\mathrm{VO}_{2} \text { peak, } \\
\mathrm{mL} \cdot \mathrm{kg}^{-1} \cdot \mathrm{min}^{-1}\end{array}$ & 85.0 (3.4)\# & $80.6(4.5)$ & $1.11^{\mathrm{M}}$ & $78.0(2.5)^{*}$ & $73.0(2.7)$ & $1.90^{\mathrm{La}}$ \\
\hline $\mathrm{VO}_{2}$ peak, $\mathrm{L} \cdot \mathrm{min}^{-1}$ & $6.38(0.42)$ & $6.09(0.44)$ & $0.67^{\mathrm{M}}$ & $5.86(0.40)$ & $5.52(0.32)$ & $0.92^{\mathrm{M}}$ \\
\hline $\mathrm{sVO}_{2}$ peak, $\mathrm{km} \cdot \mathrm{h}^{-1}$ & $14.5(0.5)$ & $14.1(0.8)$ & $0.53^{\mathrm{S}}$ & $23.9(1.9)$ & $23.8(1.8)$ & $0.09^{\mathrm{T}}$ \\
\hline $\mathrm{VE}_{\text {peak }}, \mathrm{L} \cdot \mathrm{min}^{-1}$ & $218(13)$ & $217(16)$ & $0.05^{\mathrm{T}}$ & $194(10)$ & $198(15)$ & $0.28^{\mathrm{S}}$ \\
\hline $\mathrm{RER}_{\text {peak }}$ & $1.14(0.04)$ & $1.13(0.02)$ & $0.65^{\mathrm{M}}$ & $1.06(0.04)$ & $1.05(0.03)$ & $0.09^{\mathrm{T}}$ \\
\hline $\mathrm{HR}_{\text {peak }}$, beats $\cdot \min ^{-1}$ & $193(4)$ & $189(6)$ & $0.66^{\mathrm{M}}$ & $187(6)$ & $185(8)$ & $0.21^{\mathrm{S}}$ \\
\hline$\left[\mathrm{La}_{\text {peak }}\right], \mathrm{mmol} \cdot \mathrm{L}^{-1}$ & $8.9(1.7)$ & $8.1(1.1)$ & $0.61^{\mathrm{M}}$ & $7.3(1.1)$ & $7.1(1.5)$ & $0.16^{\mathrm{S}}$ \\
\hline
\end{tabular}

Note: Data are presented as mean (SD). Abbreviations: ES, effect size; $\mathrm{VO}_{2}$ peak, peak oxygen uptake; $\mathrm{sVO}_{2}$ peak, the peak aerobic speed calculated from $\mathrm{VO}_{2}$ peak and the submaximal relationship between treadmill speed and $\mathrm{O}_{2}$ cost; $\mathrm{VE}_{\text {peak }}$, peak ventilation; $\mathrm{RER}_{\text {peak }}$, peak respiratory exchange ratio; $\mathrm{HR}_{\text {peak }}$, peak heart rate; [La peak $]$, peak blood lactate concentration. Note: Superscript letters by the ESs denote their magnitude as ${ }^{\mathrm{T}}$, trivial $(\mathrm{ES}<0.2){ }^{\mathrm{S}}$, small $(0.2 \leq \mathrm{ES}<0.6){ }^{\mathrm{M}}{ }^{\text {, }}$, moderate $(0.6 \leq \mathrm{ES}<1.2)$; and

La, large $(1.2 \leq \mathrm{ES}<2.0) .{ }^{23}$ Speed $_{\text {peak }}$ is the highest treadmill speed during the last 30 and 60 seconds for double poling and running, respectively.

*Significant difference between groups $(P \leq .01)$. \#Tendency to difference between groups $(.05<P \leq .1)$.

\section{Submaximal Data}

During submaximal DP (Table 3 and Figure 1), the $\mathrm{O}_{2}$ cost was on average $3.8 \pm 3.6 \%\left(1.8[1.7] \mathrm{mL} \cdot \mathrm{kg}^{-1} \cdot \mathrm{min}^{-1} ; F_{1,11}=5.5, P=.04\right.$; ES: 1.13) lower for the long-distance skiers than all-round skiers, with post hoc tests revealing significant differences on the 3 highest workloads $\left(16.2-19.8 \mathrm{~km} \cdot \mathrm{h}^{-1} ; P<.05\right)$ and tendencies on the 2 lowest workloads $\left(10.8-12.6 \mathrm{~km} \cdot \mathrm{h}^{-1} ; .06 \leq P \leq .09\right)$. No differences were found for $\mathrm{O}_{2}$ cost as a percentage of

Table 3 Physiological and Kinematic Responses to Double Poling at the Highest Submaximal Speed Before Exceeding Estimated Lactate Threshold $\left(2.5^{\circ}\right.$ Incline and $\left.18 \mathrm{~km} \cdot \mathrm{h}^{-1}\right)$ in All-Round and Long-Distance Skiers

\begin{tabular}{|c|c|c|c|}
\hline & All-round skiers & Long-distance skiers & ES (Cohen $d$ ) \\
\hline Power output, W & $252.3(17.4)$ & $253.7(16.3)$ & $0.08^{\mathrm{T}}$ \\
\hline $\mathrm{VO}_{2}, \mathrm{~mL} \cdot \mathrm{kg}^{-1} \cdot \mathrm{min}^{-1}$ & $56.3(1.3)^{*}$ & $54.0(2.1)$ & $1.28^{\mathrm{La}}$ \\
\hline $\mathrm{VO}_{2}, \%$ of $\mathrm{VO}_{2}$ peak-DP & $72.3(3.6)$ & $74.2(5.5)$ & $0.41^{\mathrm{S}}$ \\
\hline $\mathrm{VE}, \mathrm{L} \cdot \min ^{-1}$ & $112(17)$ & $121(18)$ & $0.56^{\mathrm{S}}$ \\
\hline RER & $0.90(0.02)$ & $0.92(0.02)$ & $0.74^{\mathrm{M}}$ \\
\hline $\mathrm{HR}$, beats $\cdot \mathrm{min}^{-1}$ & $156(8.1)$ & $159(7)$ & $0.46^{\mathrm{S}}$ \\
\hline $\mathrm{HR}, \%$ of $\mathrm{HR}_{\text {peak-DP }}$ & $83.2(3.5)$ & $85.9(2.8)$ & $0.84^{\mathrm{M}}$ \\
\hline$\left[\mathrm{La}^{-}\right], \mathrm{mmol} \cdot \mathrm{L}^{-1}$ & $1.9(0.7)$ & $1.7(0.4)$ & $0.37^{\mathrm{S}}$ \\
\hline Cycle time, ms & $1168(145)$ & $1169(78)$ & $0.01^{\mathrm{T}}$ \\
\hline Poling time, ms & $360(15)$ & $373(22)$ & $0.67^{\mathrm{M}}$ \\
\hline Poling time, $\%$ of cycle & $31(3)$ & $32(2)$ & $0.36^{\mathrm{S}}$ \\
\hline Reposition time, ms & 807 (134) & $796(68)$ & $0.12^{\mathrm{T}}$ \\
\hline Reposition time, $\%$ of cycle & $69(3)$ & $68(2)$ & $0.36^{\mathrm{S}}$ \\
\hline Cycle length, $\mathrm{m}$ & $5.8(0.7)$ & $5.8(0.4)$ & $0.01^{\mathrm{T}}$ \\
\hline ROM ankle, ${ }^{\circ}$ & $15.3(6.0)$ & $15.5(4.1)$ & $0.03^{\mathrm{T}}$ \\
\hline ROM knee, ${ }^{\circ}$ & $33.6(8.0)$ & $30.7(3.0)$ & $0.51^{\mathrm{S}}$ \\
\hline ROM hip, ${ }^{\circ}$ & $86.8(4.8)$ & $86.9(3.6)$ & $0.03^{\mathrm{T}}$ \\
\hline $\mathrm{ROM}^{\text {shoulder, }}{ }^{\circ}$ & $97.6(7.9)$ & $89.7(8.4)$ & $0.96^{\mathrm{M}}$ \\
\hline ROM elbow, ${ }^{\circ}$ & $95.7(9.2)$ & $103.4(12.2)$ & $0.70^{\mathrm{M}}$ \\
\hline zCOM displacement, $\mathrm{cm}$ & $25.6(1.4)$ & $26.7(2.6)$ & $0.50^{\mathrm{S}}$ \\
\hline
\end{tabular}

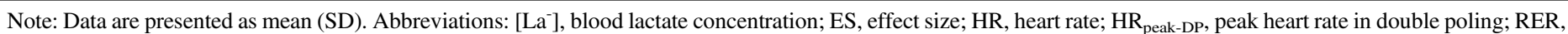
respiratory exchange ratio; $\mathrm{ROM}$, range of motion; $\mathrm{VE}$, ventilation; $\mathrm{VO}_{2}$, oxygen uptake; $\mathrm{VO}_{2}$ peak-DP, $\mathrm{VO}_{2}$ in double poling; $\mathrm{zCOM}$, vertical center of mass. Superscript letters by the ESs denote their magnitude as ${ }^{\mathrm{T}}$, trivial $(\mathrm{ES}<0.2){ }^{\mathrm{S}}{ }^{\text {, small }}(0.2 \leq \mathrm{ES}<0.6){ }^{\mathrm{M}}{ }^{\text {, moderate }}(0.6 \leq \mathrm{ES}<1.2)$; ${ }^{\mathrm{La}}$, large $(1.2 \leq \mathrm{ES}<2.0)$; and ${ }^{\mathrm{VL}}$, very large $(\mathrm{ES} \geq$ $2.0) .23 *$ Significant difference between groups $(P<.05)$. \#Tendency to difference between groups $(.05<P \leq .1)$. 
VO 2 peak-DP $\left(F_{1,11}=0.7, P=.42\right), \mathrm{HR}\left(F_{1,11}=1.3, P=.28\right),\left[\mathrm{La}^{-}\right]$ $\left(F_{1,11}=0.2, \quad P=.68\right), \quad$ respiratory exchange ratio $\left(F_{1,11}=\right.$ $2.9, P=.12)$, breathing frequency $\left(F_{1,11}=0.2, P=.67\right)$, and ventilation $\left(F_{1,11}=0.5, P=.51\right)$. When the lactate threshold was estimated as the concentration at "warm-up" $+1.8 \mathrm{mmol} \cdot \mathrm{L}^{-1}(2.7$ [0.2] $\mathrm{mmol} \cdot \mathrm{L}^{-1}$, both groups), no significant difference was found for speed (19.2 [0.7] vs $\left.19.5[0.05] \mathrm{km} \cdot \mathrm{h}^{-1} ; P=.51 ; \mathrm{ES}: 0.40\right), \mathrm{VO}_{2}$ (61.4 [2.4] vs $\left.59.1[2.0] \mathrm{mL} \cdot \mathrm{kg}^{-1} \cdot \mathrm{min}^{-1} ; P=.10 ; \mathrm{ES}: 1.03\right), \mathrm{VO}_{2}$ as a percent of $\mathrm{VO}_{2}$ peak-DP (79 [3] vs $81 \pm 5 \%$; $P=.32$; ES: 0.56 ), or HR (163 [7] vs 167 [6] beats $\mathrm{min}^{-1} ; P=.34$; ES: 0.56 ) between all-round and long-distance skiers, respectively.

The correlations between $\mathrm{O}_{2}$ cost (grand mean) in DP and age, performance (TTE) and the training hours spent in classical skiing were moderate $(r=-.37 ; P=.21 ; \mathrm{n}=13)$, high $(r=-.50 ; P=.08$; $\mathrm{n}=13)$, and very high $(r=-.82 ; P<.01 ; \mathrm{n}=9)$, respectively.

During submaximal running (Figure 1), no group differences were found for any of the cardiorespiratory variables $\left(F_{1,11}=0.01-1.3\right.$, $P=.28-.91)$. The correlations between $\mathrm{O}_{2}$ cost in running and age and performance (TTE) were moderate $(r=.32 ; P=.29 ; \mathrm{n}=13)$ and high $(r=-.60 ; P=.03 ; \mathrm{n}=13)$, respectively.

\section{DP Technique}

Neither cycle time $\left(F_{1,11}=0.03, P=.86\right)$, poling time $\left(F_{1,11}=0.5\right.$, $P=.52)$, reposition time $\left(F_{1,11}=0.2, P=.71\right)$, nor cycle length $\left(F_{1,11}=0.02, P=.88\right)$ differed between groups on the submaximal workloads (Figure 2). At the submaximal speed of $18 \mathrm{~km} \cdot \mathrm{h}^{-1}$ (the highest speed at which all subjects were below the estimated lactate threshold), the joint angles and $\mathrm{zCOM}$ were analyzed and are shown in Figure 3. No differences were found for zCOM; range of motion (ROM) of joint angles (Table 3); or the specific angles during the cycle for the ankle, knee, shoulder, and elbow (Figure 3). However, for the long-distance skiers, the hip was more flexed for $27 \%$ to $41 \%$ of the cycle $(P<.05)$, and zCOM tended to be lower for $28 \%$ to $35 \%$ of the cycle $(P \leq .10)$ compared with the all-round skiers.
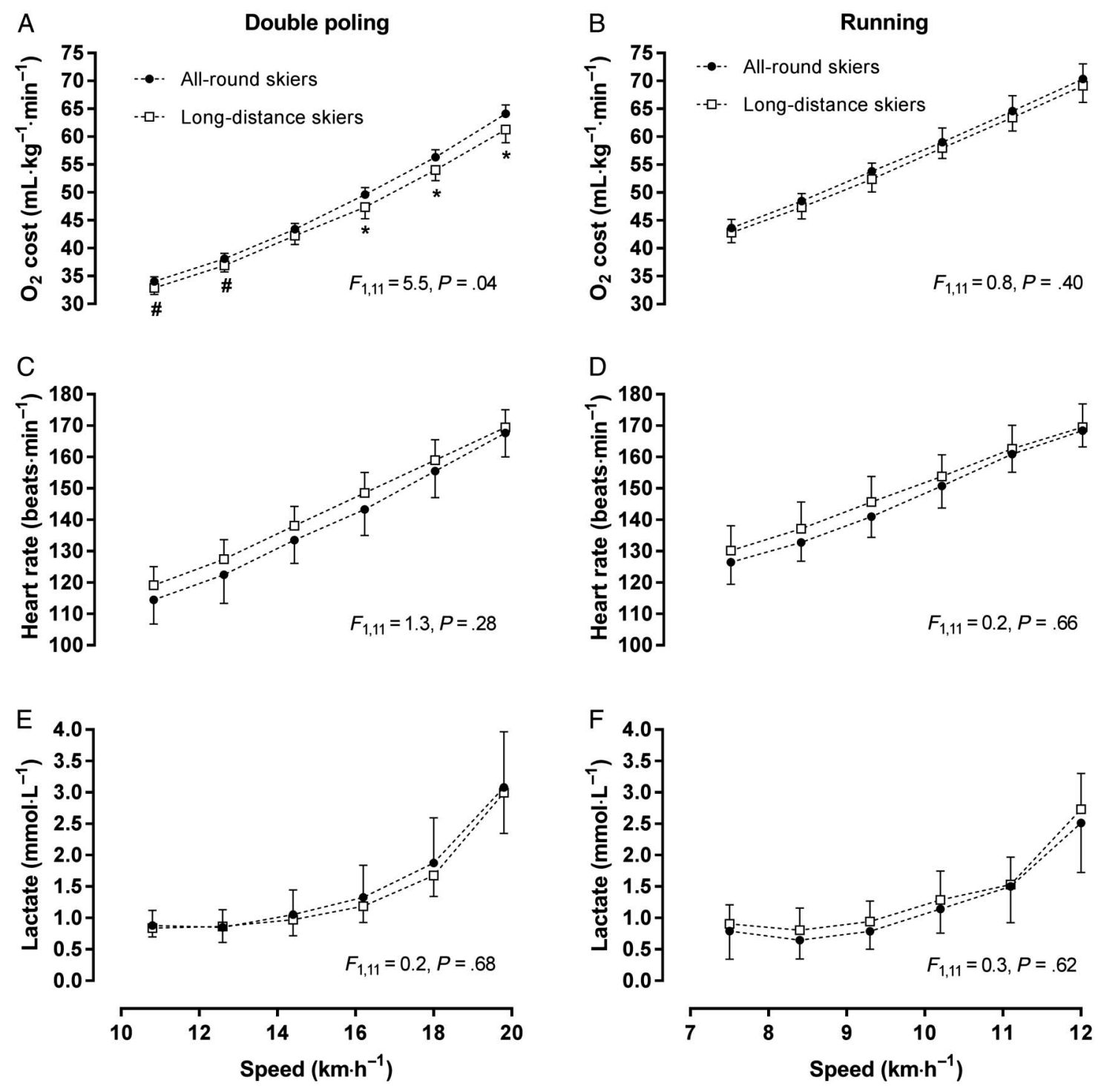

Figure 1 - Submaximal oxygen $\left(\mathrm{O}_{2}\right)$ cost, heart rate, and blood lactate concentration for all-round $(\mathrm{n}=6)$ and long-distance $(\mathrm{n}=7)$ cross-country skiers in double poling (A, C, and E) and running (B, D, and F). Values are means and error bars indicate $95 \%$ confidence intervals. *Significant difference between groups $(P<.05)$. \#Tendency to difference between groups $(.05<P \leq .1)$. 

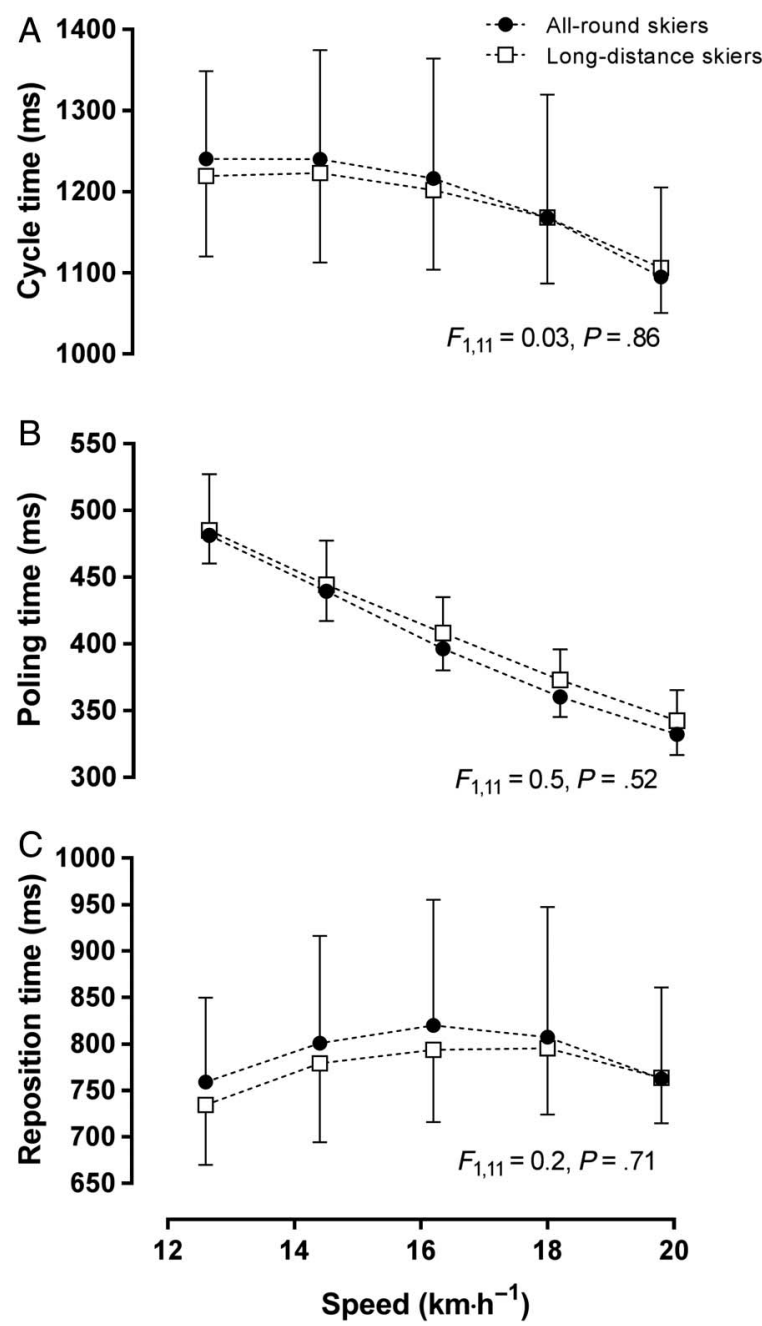

Figure 2 - Changes in cycle time (A), poling time (B), and reposition time $(C)$ by speed for all-round $(n=6)$ and long-distance $(n=7)$ crosscountry skiers. Values are means and error bars indicate $95 \%$ confidence intervals. No differences between groups were detected.

\section{Training Data}

The annual endurance, speed, and strength training are reported in Table 4. Due to the low sample size of long-distance skiers, no statistical analysis was conducted to compare groups. Compared with the all-round skiers, the long-distance skiers trained $47 \pm 67 \%$ (mean $\pm 95 \%$ confidence interval) more classical skiing $(255[25] \mathrm{h}$ vs 376 [74] h) and $64 \pm 18 \%$ less skating (255 [44] h vs 92 [11] h). However, the groups performed similar amounts of running (196 [41] h vs 187 [48] h) and other endurance training modes (61 [44] h vs 40 [22] h; for percentage distributions, see Figure 4).

\section{Discussion}

The present study provides novel information about the requirements for success in elite long-distance XC skiing: (1) low $\mathrm{O}_{2}$ cost in DP may be the key to why these skiers succeed at the longest competition durations, even though they displayed a lower $\mathrm{VO}_{2}$ peak as compared with elite all-round skiers; (2) elite longdistance skiers are characterized by a $\mathrm{VO}_{2}$ peak in running of about $80 \mathrm{~mL} \cdot \mathrm{kg}^{-1} \cdot \mathrm{min}^{-1}$, with $\sim 90 \%$ or more being utilized in DP specifically; and (3) the ratio between $\mathrm{VO}_{2}$ peak in DP and running was equal for the 2 groups, even though the long-distance skiers trained more using classical skiing in which the DP technique is heavily used.

Interestingly, the long-distance skiers displayed $\sim 5 \%$ to $6 \%$ lower $\mathrm{VO}_{2}$ peak-RUN and $\mathrm{VO}_{2}$ peak-DP than the elite all-round skiers. This could potentially be explained by several factors, including a higher standard of competitors in the WC compared with the Ski Classics, age-related differences, or different physiological demands due to competition duration. In support of the latter, WC distance and Ski Classics events were on average $\sim 19 \mathrm{~km}$ (excluding Sprint events) and $\sim 59 \mathrm{~km}$, respectively, in the season in which the athletes were tested. Hence, as exercise economy and fractional utilization of $\mathrm{VO}_{2}$ peak are known to be increasingly important with prolonged competition duration, ${ }^{29}$ it could be argued that the reduced submaximal $\mathrm{O}_{2}$ cost and similar lactate threshold as a function of speed may be of even greater importance for the long-distance skiers than an extremely high $\mathrm{VO}_{2}$ peak. Moreover, the long-distance skiers were on average $\sim 6.5$ years older than the all-round skiers, and it has been previously shown that $\mathrm{VO}_{2}$ peak can decline by approximately $\sim 5 \%$ to $10 \%$ per decade after $\sim 25$ years of age, even in trained subjects. ${ }^{30,31}$ Also, a moderate negative correlation was found between age and both $\mathrm{VO}_{2}$ peak-RUN and $\mathrm{VO}_{2}$ peak-DP, and several of the oldest long-distance skiers reported verbally that their $\mathrm{VO}_{2}$ peak-RUN had been higher at around 25 years of age. Therefore, we included age as a covariate in the statistical analysis comparing $\mathrm{VO}_{2}$ peak between groups. The adjustments for age changed the mean difference only slightly but caused a pronounced widening of the confidence intervals. Hence, this adjustment erased the statistical difference between groups only for $\mathrm{VO}_{2}$ peak-RUN and not for $\mathrm{VO}_{2}$ peak-DP. Therefore, only some of the difference in aerobic power may reflect an effect of aging (or change in training over the years), and the difference must be explained by additional factors such as differences in physiological demands due to race lengths or the standard of the athletes competing in the different race formats.

Our data contradicts the recent findings of Sagelv et $\mathrm{al}^{32}$ who found equal, if not slightly higher (ns), $\mathrm{VO}_{2}$ peak both in DP and diagonal skiing when comparing long-distance skiers to all-round skiers. However, this study only included national-class all-round skiers with mean FIS points of 121 compared with 16 in this study using elite all-round skiers. Hence, we conclude that all-round skiers have slightly higher $\mathrm{VO}_{2}$ peak values when both groups are recruited from the highest performance level.

Previously, it has been emphasized that the ability to achieve high $\mathrm{VO}_{2}$ peak/ $/ \mathrm{VO}_{2}$ max ratios in the various skiing techniques is of great importance for sport-specific performance, $, 5,18$ and it has been indicated that these ratios may be improved through increased specificity in training. ${ }^{18}$ Hence, it was appealing to hypothesize that the long-distance skiers would have a higher ratio of $\mathrm{VO}_{2}$ peak-DP/ $\mathrm{VO}_{2}$ peak-RUN than the all-round skiers. However, even though there was a difference in training-mode distribution between groups, at least based on the few athletes reporting their training, both groups showed a ratio of $\sim 0.91$ to 0.92 , comparable to the values found when comparing national class all-round skiers to elite long-distance skiers ${ }^{32}$ and to other studies investigating XC skiers at various performance levels. ${ }^{10-12}$ Moreover, there was a moderate negative correlation between $\mathrm{VO}_{2}$ peak-RUN and the ratio $\mathrm{VO}_{2}$ peak-DP/ $/ \mathrm{VO}_{2}$ peak-RUN. The reason for this is unclear and needs further elucidation. However, the findings may support the idea that DP includes too small 

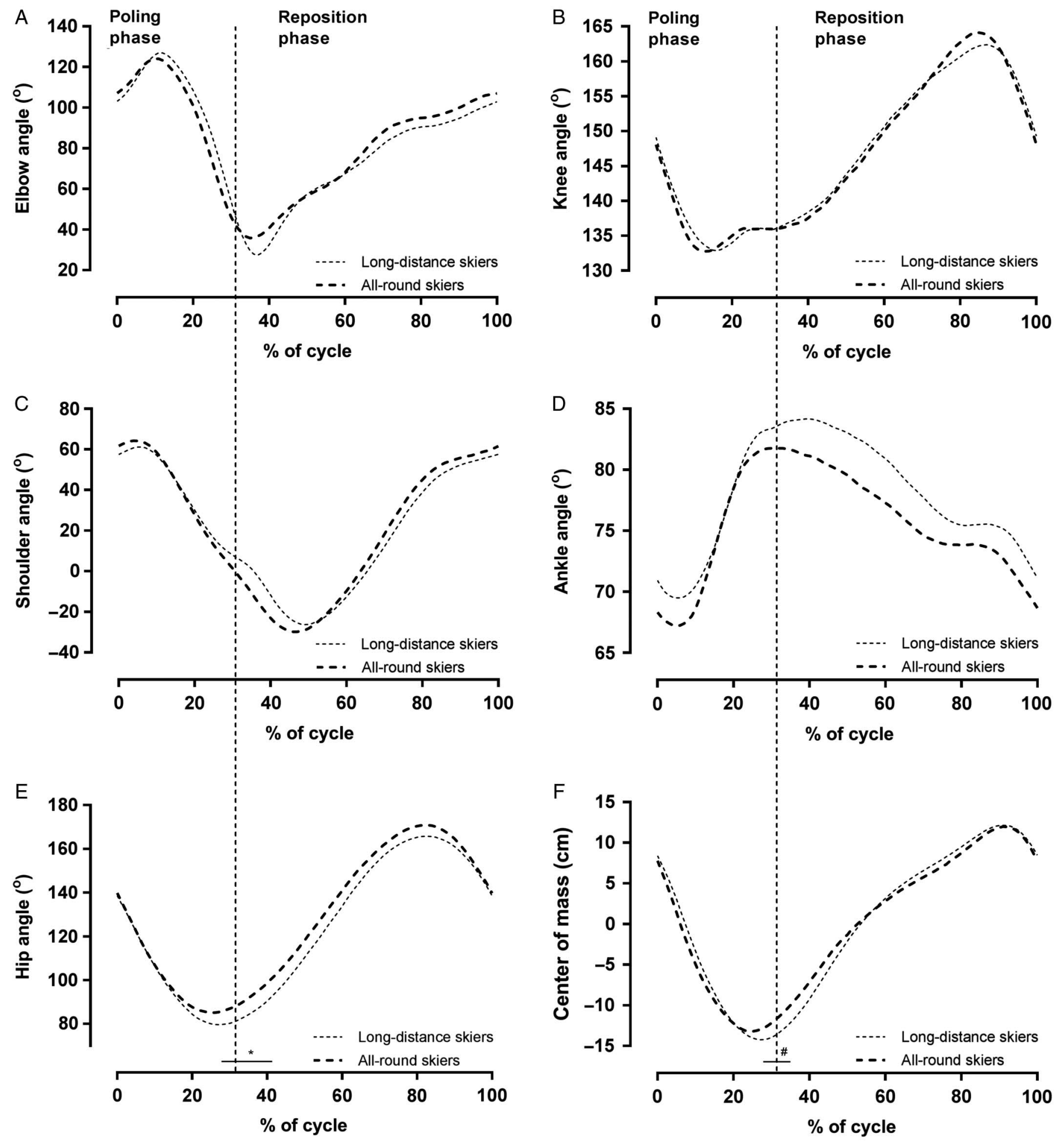

Figure 3 - Mean joint angles for the elbow (A), shoulder (C), hip (E), knee (B), and ankle (D) during double poling at $18 \mathrm{~km} \cdot \mathrm{h}^{-1}$ for all-round $(\mathrm{n}=6)$ and long-distance $(n=7)$ cross-country skiers. Figure $F$ shows the displacement of the center of mass with respect to its mean position during the cycle. The cycle starts $(0 \%)$ and ends $(100 \%)$ at pole plant, and the vertical dashed line indicates pole push-off. The horizontal line with asterisks $(*)$ indicates significant differences between groups (unpaired $t$ test, $P<.05$ ). \#Tendency to difference between groups $(.05<P \leq .1$ ).

a muscle mass to reach $\mathrm{VO}_{2}$ peak-RUN/ $\mathrm{VO}_{2} \max$ irrespective of training status or that the lower vascular conductance ${ }^{17}$ and $\mathrm{O}_{2}$ extraction ${ }^{16}$ in the upper body compared with the lower body muscles are at least not smaller in those skiers possessing the highest aerobic power.
The high correlation found between performance (TTE) and $\mathrm{O}_{2}$ cost in DP is in agreement with previous research. ${ }^{33,34}$ Similar to previous findings, ${ }^{32}$ a large difference was found in $\mathrm{DP} \mathrm{O}_{2}$ cost between groups, even though they showed almost identical cycle times, poling times, and movement patterns, as indicated by the 
Table 4 Annual Training (12 Months) for the All-Round and Long-Distance Cross-Country Skiers

\begin{tabular}{|c|c|c|c|c|}
\hline & \multicolumn{2}{|c|}{ All-round skiers $(n=6)$} & \multicolumn{2}{|c|}{ Long-distance skiers $(n=3)$} \\
\hline & Total training, $\mathbf{h}$ & $\%$ of total training & Total training, $\mathrm{h}$ & $\%$ of total training \\
\hline LIT $\left(<81 \%\right.$ of $\left.\mathrm{HR}_{\max }\right)$ & $684(72)$ & $83.1(3.3)$ & $642(97)$ & $83.0(1.8)$ \\
\hline $\operatorname{MIT}\left(82-87 \%\right.$ of $\left.\mathrm{HR}_{\max }\right)$ & $37(11)$ & $4.5(1.2)$ & $24(8)$ & $3.0(1.7)$ \\
\hline HIT $\left(>88 \%\right.$ of $\left.\mathrm{HR}_{\max }\right)$ & $32(10)$ & $3.9(1.1)$ & $43(17)$ & $5.5(1.7)$ \\
\hline Strength & $58(29)$ & $7.0(3.1)$ & $52(11)$ & $6.7(0.5)$ \\
\hline Speed & $13(9)$ & $1.5(1.1)$ & $14(8)$ & $1.8(0.9)$ \\
\hline Total training & $824(89)$ & & $775(130)$ & \\
\hline
\end{tabular}

Note: Data are presented as mean (SD). Abbreviations: HIT, high-intensity training; $\mathrm{HR}_{\max }$, maximum heart rate; LIT, low-intensity training; MIT, moderate-intensity training. Note: Due to the low number of long-distance skiers reporting their training, no statistical analysis was run. The data are merely meant to indicate trends and should be interpreted with caution.

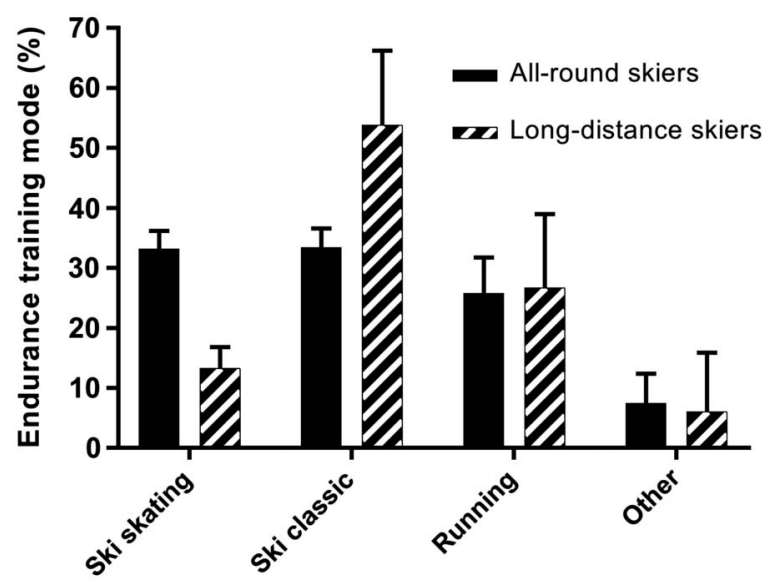

Figure 4 - Percentage distribution of annual endurance training divided between classic skiing, skating skiing, running, and other endurance training modes for all-round $(n=6)$ and long-distance $(n=3)$ cross-country skiers. Values are means and error bars indicate $95 \%$ confidence intervals. Statistical analyses were not performed due to the low sample size. The data can only be interpreted as trends and should be interpreted with caution.

joint angles and zCOM. The only technical difference observed was a lower hip angle, which caused zCOM to be slightly lower in the late poling phase for the long-distance skiers. Speculatively, some of the potential energy of elevated body mass that was released by the vertical downward movement of zCOM may have been transferred to the poles at a later part of the poling phase, characterized by a more optimal pole angle. However, without any measurement of pole-force, this is only a speculation, and we do not know if this has contributed to the observed difference in $\mathrm{O}_{2}$ cost. A limitation of this study is the low sample size, and it is possible that more kinematic differences could have been detected if we had been able to recruit more subjects. Hence, due to low statistical power, we cannot exclude undiscovered kinematic differences as a potential explanation for the observed difference in $\mathrm{O}_{2}$ cost.

Previously, a $4 \%$ to $5 \%$ lower $\mathrm{O}_{2}$ cost was found in a group of elite senior XC skiers compared with their junior counterparts. ${ }^{35}$ Plausible explanations could therefore be that greater age, or more likely, a larger accumulated training volume over several years may have contributed to the findings. In support, we observed a very high negative correlation between $\mathrm{O}_{2}$ cost in DP and the annual training hours spent during classical skiing. Also, it has previously been found that $\mathrm{XC}$ skiers reduce their $\mathrm{O}_{2}$ cost of skiing toward the competition season in parallel with an increased amount of skispecific training. ${ }^{36}$ Hence, more DP-specific training during the past years leading up to this investigation may have improved exercise economy without changing the "outward" movementpattern, potentially through mechanisms not investigated in the present study (eg, fiber-type distribution, mitochondrial efficiency, and muscle-activation patterns).

Based on the few athletes reporting their training, the longdistance skiers trained more classical skiing and less skating, which is not surprising considering the events they compete in. However, due to the small number of subjects, interpretation should be done with caution and future studies should characterize the long-distance skiers' training in more detail using a larger sample (examining factors such as distribution, intensity, and length of training sessions).

The $\left[\mathrm{La}^{-}\right]$during the submaximal workloads and the estimated lactate threshold were similar, even though each submaximal workload represented a somewhat higher percentage of $\mathrm{VO}_{2}$ peak-DP for the long-distance compared with the all-round skiers. This, together with the reduced submaximal $\mathrm{O}_{2}$ cost, resulted in equal $\mathrm{sVO}_{2}$ peak (Table 2) and equal DP performances in a short performance test, despite the lower $\mathrm{VO}_{2}$ peak. Hence, as exercise economy and the lactate threshold become increasingly important with prolonged competition duration, ${ }^{29}$ these adaptations may be of major importance for long-distance skiers' sport-specific outcomes. Moreover, improved exercise economy favors reduced energy utilization, potentially reducing the need for energy intake and use of muscle glycogen. Future studies should investigate whether these characteristics result in superior performance for long-distance skiers with prolonged test or competition durations.

\section{Practical Applications}

The present study provides valuable information regarding physiological capacities in elite long-distance skiers; a $\mathrm{VO}_{2}$ peak in DP of 70 to $75 \mathrm{~mL} \cdot \mathrm{kg}^{-1} \cdot \mathrm{min}^{-1}$ combined with an efficient exercise economy seems crucial to reach an elite performance level. In addition, the training data and communication with the best long-distance skiers indicate that a large amount of DPspecific training is crucial to improve the endurance of the upperbody muscles that may be necessary to maintain an efficient technique and high skiing speeds over several hours. In practice, this may be achieved through long training sessions mainly using the DP technique combined with sessions of upper-body core and strength training. 


\section{Conclusions}

In the present investigation, the long-distance skiers were found to have a reduced $\mathrm{O}_{2}$ cost but lower $\mathrm{VO}_{2}$ peak compared with allround skiers, ultimately leading to a similar DP performance in short performance tests. The present study challenges the idea that the ratio between $\mathrm{VO}_{2}$ peak in DP and running can be improved through increased specificity in training.

\section{Acknowledgments}

The authors would like to thank the athletes for their participation in the study. Special thanks are also given to Camilla Høivik Carlsen and Øyvind Gløersen for help with data analysis.

\section{References}

1. Maldonado S, Mujika I, Padilla S. Influence of body mass and height on the energy cost of running in highly trained middle- and long-distance runners. Int J Sports Med. 2002;23:268-272. PubMed ID: 12015627 doi:10.1055/s-2002-29083

2. Padilla S, Mujika I, Cuesta G, Goiriena JJ. Level ground and uphill cycling ability in professional road cycling. Med Sci Sports Exerc. 1999;31:878-885. PubMed ID: 10378916 doi:10.1097/00005768199906000-00017

3. Impellizzeri FM, Ebert T, Sassi A, Menaspa P, Rampinini E, Martin DT. Level ground and uphill cycling ability in elite female mountain bikers and road cyclists. Eur J Appl Physiol. 2008;102:335-341. PubMed ID: 17943306 doi:10.1007/s00421-007-0590-9

4. Losnegard T, Hallén J. Physiological differences between sprint- and distance-specialized cross-country skiers. Int J Sports Physiol Perform. 2014;9:25-31. PubMed ID: 24155024 doi:10.1123/ijspp.2013-0066

5. Sandbakk $\varnothing$, Holmberg HC. Physiological capacity and training routines of elite cross-country skiers: approaching the upper limits of human endurance. Int J Sports Physiol Perform. 2017;12:10031011. PubMed ID: 28095083 doi:10.1123/ijspp.2016-0749

6. Stöggl TL, Holmberg HC. Double-poling biomechanics of elite crosscountry skiers: flat versus uphill terrain. Med Sci Sports Exerc. 2016; 48:1580-1589. doi:10.1249/MSS.0000000000000943

7. Lindinger SJ, Holmberg HC. How do elite cross-country skiers adapt to different double poling frequencies at low to high speeds? Eur $J$ Appl Physiol. 2011;111:1103-1119. PubMed ID: 21113613 doi:10. 1007/s00421-010-1736-8

8. Zoppirolli C, Pellegrini B, Bortolan L, Schena F. Energetics and biomechanics of double poling in regional and high-level crosscountry skiers. Eur J Appl Physiol. 2015;115:969-979. PubMed ID: 25515019 doi:10.1007/s00421-014-3078-4

9. Zoppirolli C, Bortolan L, Stella F, et al. Following a long-distance classical race the whole-body kinematics of double poling by elite cross-country skiers are altered. Front Physiol. 2018;9:978. PubMed ID: 30090070 doi:10.3389/fphys.2018.00978

10. Skattebo Ø, Hallen J, Rønnestad BR, Losnegard T. Upper body heavy strength training does not affect performance in junior female crosscountry skiers. Scand J Med Sci Sports. 2016;26:1007-1016. PubMed ID: 26146761 doi:10.1111/sms.12517

11. Holmberg HC, Rosdahl H, Svedenhag J. Lung function, arterial saturation and oxygen uptake in elite cross country skiers: influence of exercise mode. Scand J Med Sci Sports. 2007;17:437-444. PubMed ID: 17040487
12. Björklund G, Stöggl T, Holmberg HC. Biomechanically influenced differences in $\mathrm{O} 2$ extraction in diagonal skiing: arm versus leg. Med Sci Sports Exerc. 2010;42:1899-1908. doi:10.1249/MSS. Ob013e3181da4339

13. Ørtenblad N, Nielsen J, Boushel R, Söderlund K, Saltin B, Holmberg HC. The muscle fiber profiles, mitochondrial content, and enzyme activities of the exceptionally well-trained arm and leg muscles of elite cross-country skiers. Front Physiol. 2018;9:1031. PubMed ID: 30116201 doi:10.3389/fphys.2018.01031

14. Van Hall G, Jensen-Urstad M, Rosdahl H, Holmberg HC, Saltin B, Calbet JA. Leg and arm lactate and substrate kinetics during exercise. Am J Physiol Endocrinol Metab. 2003;284:E193-E205. PubMed ID: 12388120 doi:10.1152/ajpendo.00273.2002

15. Mygind E. Fibre characteristics and enzyme levels of arm and leg muscles in elite cross-country skiers. Scand J Med Sci Sports. 1995;5: 76-80. PubMed ID: 7606514 doi:10.1111/j.1600-0838.1995.tb00016.x

16. Calbet JA, Holmberg HC, Rosdahl H, van Hall G, Jensen-Urstad M, Saltin B. Why do arms extract less oxygen than legs during exercise? Am J Physiol Regul Integr Comp Physiol. 2005;289:R1448-R1458. PubMed ID: 15919729 doi:10.1152/ajpregu.00824.2004

17. Calbet JA, Jensen-Urstad M, van Hall G, Holmberg HC, Rosdahl H, Saltin B. Maximal muscular vascular conductances during whole body upright exercise in humans. J Physiol. 2004;558:319-331. PubMed ID: 15121799 doi:10.1113/jphysiol.2003.059287

18. Holmberg HC. The elite cross-country skier provides unique insights into human exercise physiology. Scand J Med Sci Sports. 2015;25(suppl 4):100-109. doi:10.1111/sms.12601

19. Foss $\varnothing$, Hallén J. Validity and stability of a computerized metabolic system with mixing chamber. Int J Sports Med. 2005;26:569-575. PubMed ID: 16195991 doi:10.1055/s-2004-821317

20. Sandbakk $\emptyset$, Hegge AM, Losnegard T, Skattebo $\varnothing$, Tønnessen E, Holmberg HC. The physiological capacity of the world's highest ranked female cross-country skiers. Med Sci Sports Exerc. 2016;48:1091-1100. PubMed ID: 26741124 doi:10.1249/MSS. 0000000000000862

21. Hoffman MD, Clifford PS, Bota B, Mandli M, Jones GM. Influence of body mass on energy cost of roller skiing. Int J Sport Biomech. 1990;6:374-385. doi:10.1123/ijsb.6.4.374

22. Losnegard T, Myklebust H, Skattebo $\varnothing$, Stadheim HK, Sandbakk $\varnothing$, Hallén J. The influence of pole length on performance, $\mathrm{O}_{2}$ cost, and kinematics in double poling. Int J Sports Physiol Perform. 2016;12: 211-217. PubMed ID: 27193356 doi:10.1123/ijspp.2015-0754

23. Hopkins WG, Marshall SW, Batterham AM, Hanin J. Progressive statistics for studies in sports medicine and exercise science. Med Sci Sports Exerc. 2009;41:3-13. PubMed ID: 19092709 doi:10.1249/ MSS.0b013e31818cb278

24. Myklebust H, Losnegard T, Hallen J. Differences in V1 and V2 ski skating techniques described by accelerometers. Scand J Med Sci Sports. 2013;24:882-893. PubMed ID: 23957331 doi:10.1111/sms.12106

25. Wisløff U, Helgerud J. Methods for evaluating peak oxygen uptake and anaerobic threshold in upper body of cross-country skiers. Med Sci Sports Exerc. 1998;30:963-970. PubMed ID: 9624659

26. Helgerud J, Ingjer F, Strømme SB. Sex differences in performancematched marathon runners. Eur J Appl Physiol Occup Physiol. 1990; 61:433-439. PubMed ID: 2079063 doi:10.1007/BF00236064

27. Strømme SB, Ingjer F, Meen HD. Assessment of maximal aerobic power in specifically trained athletes. J Appl Physiol Respir Environ Exerc Physiol. 1977;42:833-837. PubMed ID: 881383 doi:10.1152/ jappl.1977.42.6.833

28. Seiler KS, Kjerland GO. Quantifying training intensity distribution in elite endurance athletes: is there evidence for an "optimal" 
distribution? Scand J Med Sci Sports. 2006;16:49-56. PubMed ID: 16430681 doi:10.1111/j.1600-0838.2004.00418.x

29. Bassett DR Jr, Howley ET. Limiting factors for maximum oxygen uptake and determinants of endurance performance. Med Sci Sports Exerc. 2000;32:70-84. PubMed ID: 10647532 doi:10.1097/00005768200001000-00012

30. Åstrand I, Åstrand PO, Hallback I, Kilbom A. Reduction in maximal oxygen uptake with age. J Appl Physiol. 1973;35:649-654. PubMed ID: 4770349 doi:10.1152/jappl.1973.35.5.649

31. Ogawa T, Spina RJ, Martin WH 3rd, et al. Effects of aging, sex, and physical training on cardiovascular responses to exercise. Circulation. 1992;86:494-503. PubMed ID: 1638717 doi:10.1161/01.CIR.86.2.494

32. Sagelv EH, Engseth TP, Pedersen S, et al. Physiological comparisons of elite male visma ski classics and national level cross-country skiers during uphill treadmill roller skiing. Front Physiol. 2018;9:1523. PubMed ID: 30505276 doi:10.3389/fphys.2018.01523
33. Sandbakk Ø, Holmberg HC, Leirdal S, Ettema G. Metabolic rate and gross efficiency at high work rates in world class and national level sprint skiers. Eur J Appl Physiol. 2010;109:473-481. PubMed ID: 20151149 doi:10.1007/s00421-010-1372-3

34. Sandbakk $\varnothing$, Hegge AM, Ettema G. The role of incline, performance level, and gender on the gross mechanical efficiency of roller ski skating. Front Physiol. 2013;4:293. PubMed ID: 24155722 doi:10. 3389/fphys.2013.00293

35. Ainegren M, Carlsson P, Tinnsten M, Laaksonen MS. Skiing economy and efficiency in recreational and elite cross-country skiers. J Strength Cond Res. 2013;27:1239-1252. PubMed ID: 22344058 doi:10.1519/JSC.0b013e31824f206c

36. Losnegard T, Myklebust H, Spencer M, Hallén J. Seasonal variations in $\mathrm{VO}_{2} \mathrm{max}, \mathrm{O}_{2}$-cost, $\mathrm{O}_{2}$-deficit, and performance in elite crosscountry skiers. J Strength Cond Res. 2013;27:1780-1790. PubMed ID: 22996025 doi:10.1519/JSC.0b013e31827368f6 